\title{
Robert Benjamin Leighton
}

Charles Peck, Gerry Neugebauer, and Rochus Vogt

Citation: 50, 9, 96 (1997); doi: 10.1063/1.881893

View online: http://dx.doi.org/10.1063/1.881893

View Table of Contents: http://physicstoday.scitation.org/toc/pto/50/9

Published by the American Institute of Physics

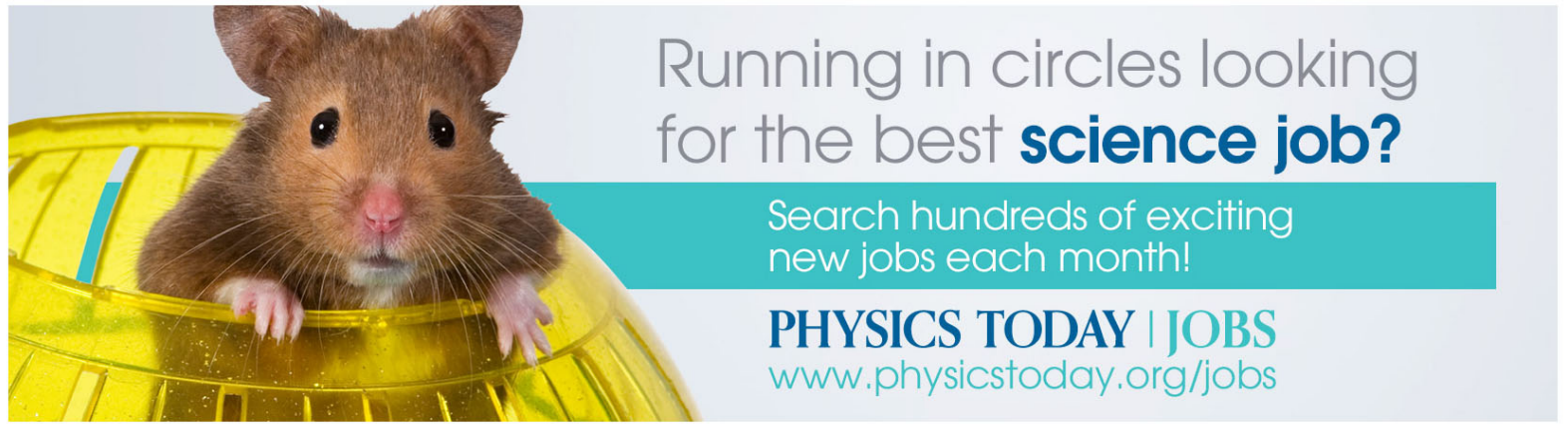


cal systems. Because of his background, he chose to study the effects of ionizing radiation on proteins, nucleic acids, viruses and bacteria. His early work made possible the estimation of the sizes and shapes of macromolecules. His research ultimately led to a more quantitative understanding of how a variety of radiations cause their damage and how organisms repair that damage. At Yale, he was largely responsible for the construction of one of the first cyclotrons to produce a beam of radiation. He used deuterons and alpha particles from the cyclotron in many of his early studies.

Pollard was a versatile writer, producing textbooks on such subjects as microwave radiation, nuclear physics, physics for nonscientists, the physics of viruses and molecular biophysics. In addition, he served as president of the Biophysical Society (1959-60) and of the Radiation Research Society (1961-62). In the early 1950 s, he was chairman of the Democratic party's committee on science and technology.

Pollard displayed a rare combination of humor, wisdom and sharp analytical intellect, as well as a dedication to the preservation of the human spirit. The missionary zeal of his parents was reflected in his commitment to excellence in all that he did. His legacy to science is that of a humanist, mentor, teacher and scholar, and it lives on in the works of those who knew him and continue in his footsteps.

Stanley Person Johns Hopkins University Baltimore, Maryland

HAROLD MOROWITZ George Mason University Fairfax, Virginia

\section{Robert Benjamin Leighton}

R obert Benjamin Leighton, a longRtime physicist and astronomer at Caltech, died in Pasadena on 9 March 1997 of a neurological disease.

Bob was born in Detroit on 10 September 1919 and received his physics undergraduate (BS, 1941) and graduate (MS, 1944; PhD, 1947) degrees from Caltech. He stayed at Caltech his entire professional career, serving as division chair of physics, mathematics and astronomy from 1970 to 1975 and retiring as the Valentine Professor of Physics in 1985.

Bob was the consummate physicist, interested in a large variety of subfields within physics which he approached in profound, original and bold ways, often opening entirely new scientific disciplines. He inspired others

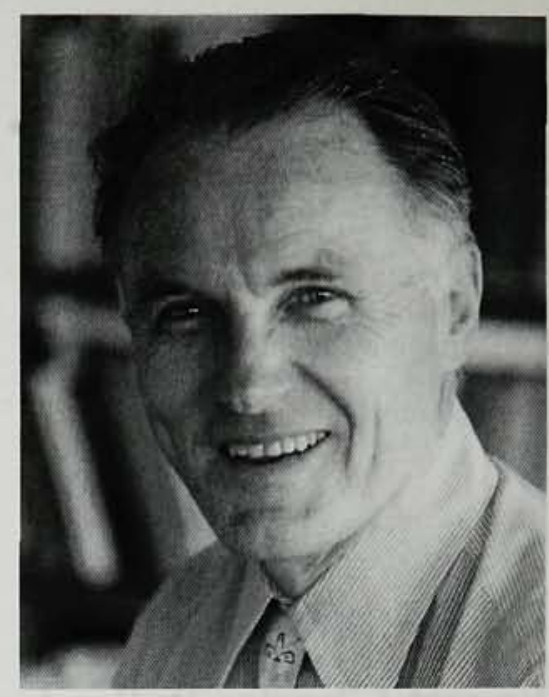

ROBERT BENJAMIN LEIGHTON

with an infectious joy for physics. His doctoral thesis was related to the specific heat of face-centered cubic crystals, and during World War II, he worked in a Caltech group designing and testing solid propellant rockets. In 1948, he joined Caltech's cosmic-ray group under Carl Anderson's leadership, and in 1949 played a key role in showing that the mu-meson decay products are two neutrinos and an electron. In 1950, he used cloud chambers to measure "V" particle (strange particle) decays, after the initial discovery of two cases in England in 1947. Over the next seven years, he elucidated many of the properties of such new strange particles as the $\Lambda$, the $\Xi$ and what were then called the $\Theta$ particles (K-mesons).

About 1956, Bob became interested in the physics of the outer layers of the Sun. With characteristic imagination and insight, he devised Doppler shift and Zeeman effect solar cameras. They were applied with striking success to the investigation of magnetic and velocity fields on the Sun. With the Zeeman camera, Bob and his students mapped complicated patterns of the Sun's magnetic field with excellent resolution. Even more striking were Bob's discoveries of a remarkable fiveminute oscillation in local surface velocities and of a "super-granulation pattern" of horizontal convection currents in large cells of moving material. These solar oscillations have subsequently been recognized as internally trapped acoustic waves, opening up the whole new field of solar seismology. His work led to the formation of the Big Bear Solar Observatory.

In the early $1960 \mathrm{~s}$, Bob fabricated a 62-inch telescope, based on the hardening of spinning epoxy, for use at infrared wavelengths. This innovative telescope, located on Mount Wilson, was used to produce the first all-sky survey at $2.2 \mu \mathrm{m}$. Although most professionals predicted that only a few sources would be detected, this survey revealed thousands of relatively cool objects. Thus, Bob effectively started and nurtured the new field of infrared astronomy at Caltech.

During the mid-1960s, Bob was the team leader at the Jet Propulsion Laboratory for the imaging science investigations on the Mariner 4, 6 and 7 missions to Mars. He played a key role in forming and guiding the development of JPL's first digital television system for use in deep space. He also contributed to the first efforts at image processing and enhancement techniques made possible by the digital form of the imaging data. He demonstrated numerically the role of dry ice in the Martian polar caps and atmosphere.

In the 1970 s, Bob's interest shifted to the development of large, inexpensive, yet relatively accurate antennas that could be used to pursue millimeter-wave interferometry and submillimeter-wave astronomy. Once again, his remarkable experimental abilities opened a new field of science at Caltech that continues to be vigorously pursued at both the Owens Valley Radio Observatory and the Caltech Submillimeter Observatory on Mauna Kea in Hawaii, both of which use so-called Leighton 10 meter dishes.

Bob was a renowned and popular teacher, authoring a highly influential text, Principles of Modern Physics (McGraw-Hill, 1959) and, together with Richard Feynman and Matthew Sands, editing The Feynman Lectures on Physics (Addison-Wesley, 1965). For his contemporaries, Bob set a high standard of teaching. He and Victor Neher developed frictionless air bearings for demonstrating the conservation of momentum and energy in laboratory collisions. Those bearings were the forerunners of the air bearings that Bob used to polish telescope mirrors.

Bob loved nature and music and was an avid hiker. He carried his experimental skills beyond the laboratory and built his house with his own hands.

All of Bob's work was marked by a uniqueness and innovation. He was generous with ideas and credit. In the areas he touched, he left behind a legacy of achievement and a fresh beginning. Many of us owe our start in science to his guidance, wisdom and encouragement. Every day at Caltech brings a new reminder of Bob. All who knew him miss him.

Charles Peck
Gerry NeUGEBAUER
Rochus VoGT
California Institute of Technology
Pasadena, California

Charles Peck RochUS VOGT Pasadena, California 